\title{
Octopus Clubfoot Rediscovered - World's First Exotic Case - A Neglected, Triple Axes Rotational, Grade 3 Extreme Deformity: Corrected by, Unparalleled, 4-In-1 Mega Surgical Skin Expansion from Crooked to ROZY Foot
}

ISSN: 2576-8875

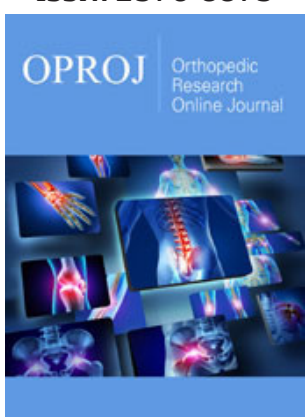

${ }^{* 1}$ Corresponding author: Mittal $\mathrm{RL}$ Department of Orthopaedics, Emeritus Professor GOMCO Patiala (Punjab) Mittal Ortho Centre 97 New Lal Bagh Patiala (Punjab), 147001, India

Submission: 傮 August 30, 2019

Published: 制September 11, 2019

Volume 6 - Issue 1

How to cite this article: Mittal RL. Octopus Clubfoot Rediscovered - World's First Exotic Case - A Neglected, Triple Axes Rotational, Grade 3 Extreme Deformity: Corrected by, Unparalleled, 4-In-1 Mega Surgical Skin Expansion from Crooked to ROZY Foot. Ortho Res Online J. 6(1). OPROJ.000627.2019.

DOI: 10.31031/OPROJ.2019.06.000627

Copyright@: Mittal RL, This article is distributed under the terms of the Creative Commons Attribution 4.0 International License, which permits unrestricted use and redistribution provided that the original author and source are credited.
Mittal RL*

Emeritus Professor Orthopaedics, GOMCO Patiala, India

\section{Abstract}

Octopus clubfoot is the world's first, the most spectacular severe/ rigid BIZARRE deformity with this new catchy name given by the author. This 18-year-old girl was operated by 4-in-1 unifying incision (first ever four well known plastic surgery procedures in one incision) with excellent, extremely gratifying, normal looking foot, without any arthrodesis. During The Intervening Period, Numerous, Highly Significant, Firsts Were Discovered relating to this case, having potential for changing global thinking of treating varied neglected deformities, prevalent globally, more in LMICs (as reported in author's SICOT article at (Table 1) and Clubfoot Book by Taylor \& Francis 2018, available, the world over, on Google search). It displayed an AWESOME SHOW IN PRINT MEDIA AND GOOGLE IN ITS FIRST DISCOVERY. It is expected that. RETRIEVAL OF THIS NATURE'S FREAK NEEDS A LOUD REAWAKENING CALL, because of potential TO BE A GAME CHANGER IN THE HISTORY OF CLUBFOOT MANAGEMENT.

This graded unification of rotation flap, Z-plasty, VY-plasty and fillet flap, is not only a treatment of this case, but also a surgical concept. This can achieve requisite enlargement of contracted skin chamber in any Crooked Clubfoot. In other words, it may be only Rotation flap or in combination with other three as 2,3 , or 4-in-1 incision. This is reproducible too in any, severest of severe deformity, at any age from one year to late adulthood. Author has been actually doing this and documented too. Each one of the four, enlarges skin container, complementing each other for maximum enlargement of fascio-cutaneous room. However, deeper corrections are no less important, which become easier; achieving a longer, flexible and good shape foot, without arthrodesis. Therefore, OCTOPUS CLUBFOOT, incarcerated, like in a cell, in the pages of SICOT journal and Clubfoot book, need to come out into the open sky to become visible worldwide highlighting this surgical concept for clubfoot community and care givers. An ugly Crooked Foot can be converted in to a pleasing ROZY Foot. ROZY is an ACRONYM FROM Rotation, Z-plasty and vY-plasty of SKIN CHAMBER and Crooked depicts the annoying feeling of this deformity.

\section{Introduction}

Author has been researching in this grey area of Trimorphic Extreme Clubfoot Deformities since more than 50 years. This nomenclature was given by the author Mittal [1] for 3 grades of this deformity, which are prevalent, worldwide, in all LMICs and $80 \%$ of global population. They form a big chunk of the whole, remaining uncorrected, under-corrected or relapsing with age to the tune of 95\% Tarraf [2] as reported in literature under various names, for want of a good/ acceptable surgical treatment They are commonly seen in LMICs with millions of DALYs wasted \& GBD Ponseti [3]. The most important reason discovered for failures has been the neglect of contracted fascio-cutaneous foot \& ankle chamber of varying severity/ rigidity. New surgical techniques were invented, with groundbreaking achievements of innumerable global presentations/ publications Mittal [4-6] with many awards/ rewards. This research has been accomplished in THREE PHASES: first phase for about 25 years in grade $1,2^{\text {nd }}$ phase about 15 years in grade 2 and the third phase in grade 3 extreme deformities, with landmark unique achievements (still continuing). The third phase has been the most significant.

Rotation flaps, Z-plasty, VY-plasty and Fillet flaps, well known four plastic surgery procedures, are frequently used as single procedures in cases of skin loss in the limbs, due to trauma, but have never been unified as two, three or all fours by any surgeon. This is the one and the only case, where all four procedures have been used by any orthopedic surgeon. It is 
also concluded that there is a great potential for continued research in clubfoot.

\section{Patient \& Methods}

RK 18Y, F, Congenital Clubfoot with polydactyly (8 toes), with scary looks and other multiple deformities, remained untreated/ neglected, as a surgical enigma. A Catchy new name was given to it as Octopus Clubfoot and is the first such case in the world.

\section{On examination}

Left sided, 8 toed, Grade 3 extreme equinovarus deformity, patient standing on lateral border with 2 callosities at 5TH MTP joint \& CC joints, with about $90^{\circ}$, COMPLEX and coupled, triple axes rotation: in transverse., anteroposterior and vertical, sole facing directly backward and heel almost vertical and great toe, parallel with tibia, in extreme metatarsus varus, $2 \frac{1}{2} 2$ " shortening of lower limb with total hypoplasia \& wind-swipe deformity towards the right knee. X-rays showed- 8 toes, Intertarsal fusions as: medial two metatarsals fused at near their heads, while $2^{\text {nd }}, 3^{\text {rd }}, 4^{\text {th }}$ and $5^{\text {th }}$ at their shafts, about $90^{\circ}$ hallux varus, Fifth Metatarsal is angulated in valgus to support the distal callosity, other metatarsals in varus. Skiagram \& Footprint looked starry like an octopus (Figure 1a-1h).

\section{Surgery}

Meticulous 4-in-1 mega skin expanding incision, one after another i.e. Dolar (Dorsolateral Rotation skin flap) + Z+ VY-plasty+ fillet flap, extremely contracted tibialis posterior tendon fanning out in sole, meticulous surgery to cover gaping posteromedial raw area. Deeper releases: extensive posteromedial, lateral and plantar were done as described in the author's book, filleting out of extra bony s-shaped structure of toes shaved off with an osteotome from first toe, Hallux Varus release were done, Dorsolateral cuboid wedge resected. Multiple K-wires were used to keep hallux varus, tarsal reductions and calcaneocuboid area \& bones fixed in corrected position.

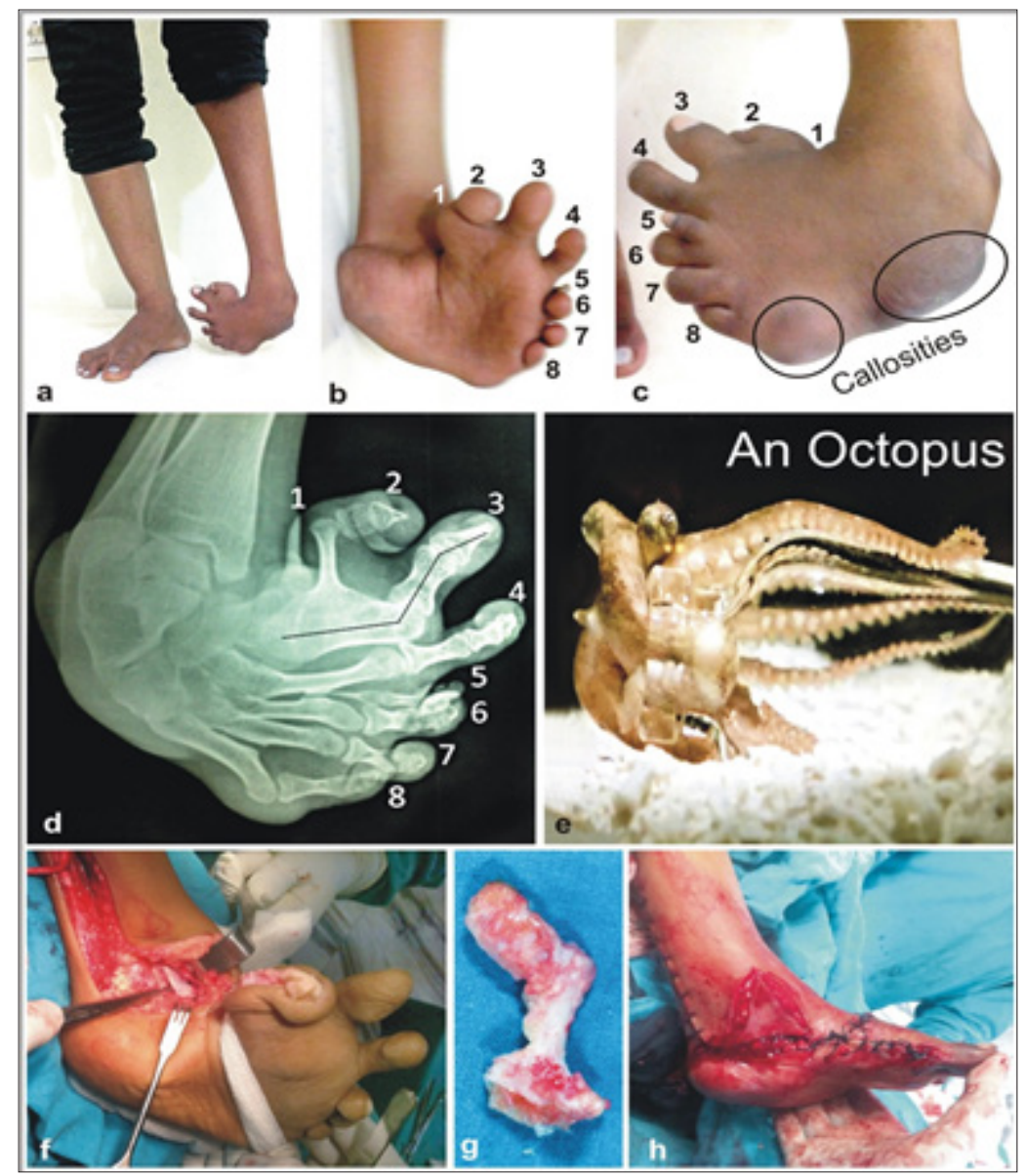

Figure 1: Reprinted from figure 5.19 a to h from author's clubfoot book.

Description of Figure $\mathbf{5 . 1 9}$ a to $\mathbf{h}$ : a to c- Clubfoot with 8 toes, coupled rotation of foot at $90^{\circ}$ on double axes with dorsum facing directly forward and sole backwards and two highlighted weight bearing callosities; d - X-ray showing 8 toes and varus of great toe with angular deformities of metatarsals and coalitions are seen; e- An Octopus, its body parts, resembling foot bones in X-ray can be well compared; f- Highly contracted and short tibialis posterior fanning out in to the sole is visible; g- Excised/ Filleted out bones (pre-axial extra toes from the fused first metatarsal) from the fillet skin flap; h- Four - in - one i.e. DOLAR $+Z+V Y+$ Fillet flap used to provide healthy $\&$ adequate skin cover for the wide posteromedial gap, making possible complete opened out deeper correction. Healthy bleeding pink V shaped incision can be seen. 


\section{Result}

Showed FULL CORRECTION at 1 $1 \frac{1}{2}$ years follow up: maximum foot length without any fusion, fully satisfied patient, walking with
2" shoe raise (foot smaller). Foot bones are quite mobile $\&$ can be improved further by undoing the remaining congenital intermetatarsal fusions, limb lengthening is also possible. Patient is unwilling at present for other surgeries, due to fear of pain (Figure 2i-q).

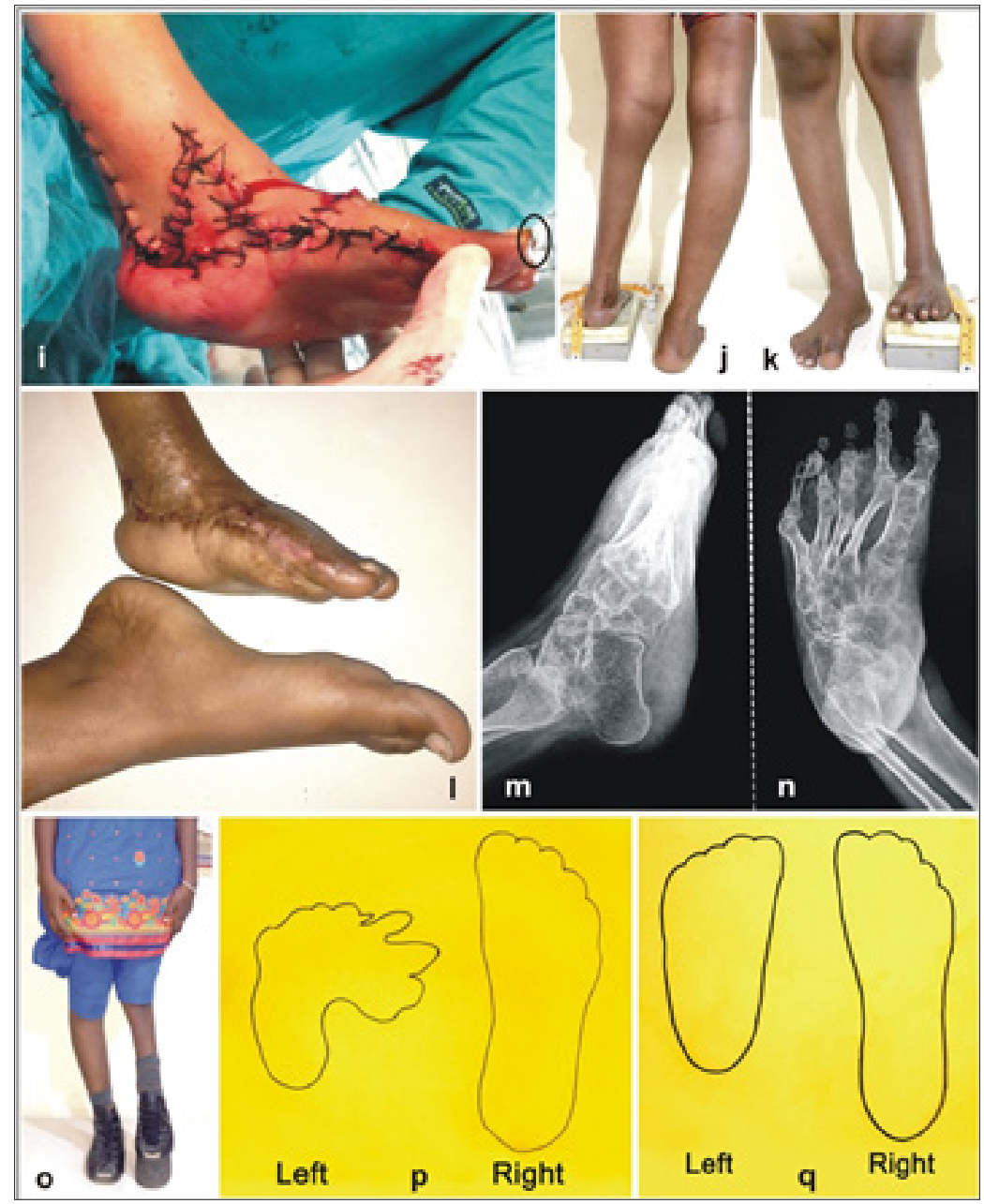

Figure 2: Reprinted figure 5.19 (B) i to q from author's Clubfoot Book.

Description of Fig 2 i to q: i- 4-in 1 flaps wounds closed and hallux varus also corrected with a highlighted K-wire in the great toe. $\mathrm{j}$ to 1 - showing corrected deformity in various views, with $2 \frac{1}{2}$ inches shortening with patient standing and wind- swipe deformity; $\mathrm{m} \& \mathrm{n}$ - skiagrams AP and Lateral views showing corrected deformity and intertarsal coalition with angulated 5th metatarsal as the second callosity site: o- At one year follow up patient walking with 2" shoe raise and is highly satisfied, not willing for limb lengthening for the present; $\mathrm{p}$ and q- Foot prints of weight bearing areas of deformed foot and corrected foot compared with normal side. Deformity has been very well corrected except for a smaller size.

Discussion \& Conclusion

\section{Discussion}

Orthopaedics and plastic surgery have a very close, like hand in glove, relation as regards the four plastic skin procedures. They are commonly used in surgery of limbs in trauma and birth defects, but they have always been used singly. In the present research, evidence based, graded fusion of all fours, depending upon the amount of skin contracture, has been made possible. Octopus Clubfoot was the most extreme scary deformity, where in this unified incision has been successfully accomplished. Ample evidence exists, as numerous references in many National/ International plastic surgery Journals, including Annals of National Academy Medical
Sciences, Ponten 1981 PMID- 7246984, BJPS 34:215-20 and many other articles with cross references, notably of Bhattacharya (well-known Plastic surgeon of BHU Varanasi in IJPS in 2010, Doi. 10.4103/0970-0358.73424, and ANAMS (India) 52(4):222231, Oct-Dec 2016. All these have been quoted in author's Clubfoot BOOK \& SICOT publications.

THIS IS THE WORLD'S MOST PUBLICIZED SPECTACULAR CLUBFOOT CASE, A NATURE'S FREAK, HAVING A HIGH ACADEMIC VALUE WITH A FUTURE FOR TREATING ALL CLUBFOOT DEFORMITIES OF ANY RIGIDITY \& SEVERITY AT ALL AGES. THERE ARE NUMEROUS UNUSUAL FIRSTS, ASSOCIATED WITH THIS CASE, WHICH NEED TO BE HIGHLIGHTED: 
a) Octopus clubfoot is the first the most eye-catching case, viral on Google search deserving more Global attention.

b) It reminds once again the taboo/ superstitions, prevalent in LMICs and left as untouchable, helplessly considering it a nature's wrath.

c) This was one of the poor free surgeries, out of 38 clubfoot surgeries under Government of India's National Health Mission scheme. Author was given special permission by Government due to his expertise.

d) First clubfoot case highlighted by National/ International media. In India: e.g. Hindustan times, The Tribune, Deccan chronicale A london daily publication: Dailymail Interviewed this patient, at Patiala, details available at LINK "dailymail. co.uk/ health octopus clubfoot" with many pictures. All these are viral on Google search as well as U tube on simply looking for octopus clubfoot.

e) It can be seen at No 8, (Table-1) (doi 10.1007/s00264017-3741-6), International Orthopaedics (SICOT) June 2018 Issue, author's article.

f) Also, in AUTHOR's book on clubfoot, written for Taylor \& francis, a premier Global Publisher, released on 29th Nov, at Coimbatore IOACON 2018. This is available for sale all over the world on Google search at about one hundred sites: ISBN 9781138083738.

g) This is the first most crooked clubfoot deformity, corrected by any surgeon, using 4-in-1 unified incision and achieving quadruple mega expansion, each in 3D with the best possible correction without arthrodesis.

h) This is a broad based surgical concept and not just a treatment for this particular case, which has opened floodgates for future use of this technique for all others, severest of severe and rigid clubfoot deformities at any Age, achieving a Rozy Foot from a Crooked Clubfoot. i) This is first ever using all the four plastic surgery procedures by any orthopaedic surgeon or not even a plastic surgeon. In clubfoot too, of course, this is for the first-time use.

j) First ever, Indian Orthopaedic Association all three Awards for this 4- in- I research: Silver Jubilee in 1988, Golden in 2013 and Diamond in 2018.

k) Appointment as Emeritus Professor at GOMCO Patiala for poor free surgeries, due to this research.

\section{Acknowledgement}

Both Figure 1 \& 2- Reprinted/adapted by kind courtesy Springer Nature and Copyright clearance centre of Rights Link. From author's own published article; Mittal RL [1,4-6]. Trimorphic extreme clubfoot deformities and their management by triple surgical skin expanders-Dolar, Olarz and Dolar-E (evidence based mega-correction without arthrodesis). DOI 10.1007/s00264-0173741-6. As well as kind Courtesy of Taylor \& Francis group (CRS Press) adopted from author's own book Clubfoot-A comprehensive approach past present \& future: ${ }^{\text {st }}$ edition, by Mittal RL [1].

\section{References}

1. Mittal RL (2018) Trimorphic extreme clubfoot deformities and their management by triple surgical skin expanders- Dolar, Dolarz and Dolarz-E (evidence based mega corrections without arthrodesis). International Orthopaedics (SICOT) 42(6): 1297-1306.

2. Tarraf YN, Carroll NC (1992) Analysis of the components of residual deformity in clubfeet presenting for reoperation. J Pediatr Orthop 12(2): 207-216.

3. Ponseti IV, Zhivkov M, Davis N, Sinclair M, Dobbs MB, et al. (2006) Treatment of the complex idiopathic clubfoot. Clin Orthop Relat Res 451:171176.

4. Mittal RL, Makhni SS, Sidhu GS (1981) Morbid anatomy of congenital clubfoot. Ind J Orthop 15(2): 129-135.

5. Mittal RL (1987) The surgical management of resistant clubfoot by rotation skin flap and extensive soft tissue release. Int Orthop 11(3): 189192.

6. Mittal RL (2014) Obstinate clubfoot with triple plus dislocation. J Foot Ankle Surg (Asia Pacific)1(2): 72-77. 